\title{
Capítulo V Institucionalidad del terrorismo: una controversial aproximación
}

Tedo fenómeno asimétrico tiene un nivel de gestación corporal enmo, por ser uno de los problemas a los que se enfrentan las sociedades contemporáneas, logra integrar una serie de instrumentos estructurales que lo hacen complejo y volátil, de allí que sea tan gaseoso.

Para lograr entender el terrorismo hay que escudriñar más allá de saber cuántas o cuáles son las organizaciones terroristas en el mundo. Hay que entender la fenomenología y los vasos comunicantes que hacen de este fenómeno un gran reto y desafío para el derecho internacional, la seguridad, las relaciones internacionales y un cúmulo denso de dimensiones analíticas y políticas.

Es importante reconocer que el terrorismo es un método más complejo, que posee fuerzas motrices de un régimen internacional subterráneo y, siguiendo dicha lógica, al ser un régimen tiene sub-instituciones que se configuran como un sistema nervioso y circulatorio, por donde fluyen los suministros materiales e inmateriales ${ }^{21}$ alrededor del mundo.

Aunque parezca irrisorio advertir que el terrorismo tiene instituciones por tener elementos exclusivos de la convencionalidad y de los

21 Los suministros inmateriales son entendidos como los apoyos ideológicos y políticos de determinados grupos y sus actos. 
actores regulares como los Estados u organizaciones, es fundamental identificar su arquitectura subterránea como institucionalidad, debido a que de ese modo es más digerible el entendimiento de su actividad terrorista. Si se logra entender lo subterráneo en la traducción convencional es más fácil identificar el sistema terrorista global.

Las instituciones son los ejes medulares y angulares de toda organización, y el terrorismo no carece de estas. Claramente, por ellas se entiende que son los elementos materiales e inmateriales que le otorgan la funcionalidad al sistema como las normas, los códigos de acción, los actores involucrados, los símbolos, la cosmovisión como su forma de entender y ver el mundo, la metodología para el financiamiento y en sí forjar la arquitectura de régimen internacional y sistema subterráneo.

No obstante, si bien no hay ningún aparato científico o estudio que advierta y simule al terrorismo como una institución (o que esté compuesto por estas) porque es arriesgado advertirlo de esa manera, dicha configuración es importante para entender su funcionamiento a gran y pequeña escala; es imperante analizar al terrorismo desde otra óptica, quizás para encontrar el punto débil y poder atacar su funcionamiento. Es por tal razón que el terrorismo puede entenderse desde la consolidación de instituciones subterráneas. En ese sentido, el terrorismo es vigente.

\section{Institución virtual: Internet como rampa estratégica del terrorismo}

Configurar el terrorismo en un marco de instituciones parece ser un reto bastante cuestionable. No obstante, son las instituciones subterráneas las que le otorgan al terrorismo su carácter efectivo en la funcionalidad y viralización de sus actos de alcance regional y global.

De esa manera, el terrorismo tiene que valerse de instrumentos de diferente naturaleza para poder proyectar sus planes, enviar los mensajes estratégicos en cuestión de segundos y para lograr masificar sus políticas de terror sin arriesgar demasiados elementos; es decir, el terrorismo busca crear o copar instituciones ya existentes para eliminar 
los costos de transacciones a todo nivel. Para dicho fin, las organizaciones terroristas se valen de instituciones virtuales como Internet ${ }^{22}$ para hacer de sus mensajes el punto de fuga de sus métodos.

Con la globalización y el evidente advenimiento de Internet en particular, han aumentado significativamente las oportunidades para que los terroristas puedan asegurar la publicidad de sus actos (Conway, 2006). Los foros y portales de Internet configuran una pieza fundamental dentro de la estrategia comunicativa del terrorismo en general (Torres, 2013). Es la infraestructura más utilizada metodológicamente por los grupos terroristas para diversificar sus canales de comunicación y potenciar su mensaje.

Internet ha ampliado significativamente las posibilidades de conseguir publicidad por parte de los grupos terroristas. Antes de la llegada de Internet, las esperanzas de conseguir publicidad para sus causas y acciones dependían [sic] de lograr la atención de la televisión, la radio y la prensa. Ahora, el hecho de que los propios terroristas controlen de manera directa el contenido de sus sedes les proporciona mayores posibilidades de influenciar el modo en que son percibidos por distintos tipos de público objetivo y manipular su imagen y las de sus enemigos (Weimann, 2004).

La globalización ha traído consigo grandes avances para la humanidad en materia de comunicaciones, tecnología y accesibilidad a recursos de manera más fácil y eficaz; no obstante, también las amenazas que padece la humanidad se mueven tectónicamente con mayor facilidad vulnerando las capacidades de reacción de los Estados, las instituciones, las organizaciones y en sí la de todos los operadores de justicia y seguridad. Tal es el caso del terrorismo que se ha valido de la Internet para hacerlo.

22 Para el mundo convencional, Internet es una red de redes, o simplemente la interconectividad para transmitir datos e información. No obstante, para efectos subterráneos como los del terrorismo, Internet es más que una red, es la plataforma estratégica para ellos y por ende una institución que les permite estar relativamente seguros. 
Una de las preguntas estratégicas que vale la pena plantearse es ¿por qué los grupos terroristas usan Internet sabiendo que es un sistema de fácil detección por parte de los operadores de seguridad? Pues bien, la respuesta al cuestionamiento es múltiple y variada. En primer lugar, los grupos terroristas se valen de esta herramienta sencillamente para eliminar los costos de transacción que tendría la elaboración de una sola y exclusiva plataforma de comunicaciones, al estilo de la inteligencia militar; por otra parte, los grupos terroristas usan Internet como estrategia de distracción para los Estados y/o autoridades que les siguen el rastro para su desmantelamiento.

Pero el uso de Internet de manera subterránea, para efectos terroristas, tiene una connotación aún mayor que dichos grupos han trazado como objetivo estratégico. Así como las instituciones legales y legítimas, que hacen parte del statu quo del sistema internacional, tienen plataformas para masificar la información a través de Internet y el ciber-espacio, el terrorismo también ha tejido una "institución subterránea" para que funja como plataforma estratégica en sus mensajes y vehículos de comunicación.

Tabla 4. Algunos usos y dimensiones de la Internet por parte de los terroristas

\begin{tabular}{|l|l|}
\hline \multicolumn{1}{|c|}{ Usos } & \multicolumn{1}{c|}{ Dimensiones } \\
\hline Propaganda & $\begin{array}{l}\text { Reclutamiento } \\
\text { Incitación } \\
\text { Radicalización }\end{array}$ \\
\hline Financiación & Apoyo financiero \\
\hline Adiestramiento & Instructivos \\
\hline Planificación & $\begin{array}{l}\text { Comunicaciones secretas preparatorias } \\
\text { Información de dominio público }\end{array}$ \\
\hline Ejecución & Desarrollo de planes \\
\hline Ciber-ataques & Nueva dimensión del terrorismo \\
\hline
\end{tabular}

Fuente: UNODC, (2013).

Internet, al ser un medio estratégico y una plataforma plausible para sus fines de terror, articula una serie de usos y dimensiones relevantes. 
En ese orden, basta analizar las implicaciones y metodologías del terrorismo para hacer de la Red una institución. Así las cosas, uno de los usos más habituales de Internet por parte de los grupos terroristas es la propaganda.

\section{La propaganda}

Es un medio empleado para llegar de manera viral a los objetivos estratégicos. A través de la propaganda, los grupos potencian sus actividades con la intención de "seducir" a un interlocutor débil y maleable. La identificación de su interlocutor está basada en un uso racional en la consecución de adeptos y apoyos de todo nivel. En ese orden de ideas, los terroristas seducen desde pequeños y jóvenes hasta las personas más grandes, es decir, no discriminan condición, raza, edad, credo e incluso — así parezca absurdo— también religión para llegar con un mensaje cautivador, dependiendo del público al que buscan captar. Una de sus intenciones, a gran escala, es justificar sus actividades convirtiendo su naturaleza y configuración en un "estilo de vida" alternativo, paralelo pero subterráneo.

Esta generalmente adopta la forma de comunicaciones de audio y video, que imparten instrucción ideológica o práctica, dan explicaciones y justificaciones o promueven actividades terroristas. El material puede consistir en mensajes, presentaciones, revistas, tratados, ficheros de video y audio virtuales, y en juegos de video elaborados por organizaciones terroristas o sus simpatizantes (UNODC, 2013).

Esta es otra manera de hacer terrorismo. En ese orden de ideas, no hace falta con hacer explotar un artefacto o asesinar a alguien para determinar que las acciones comunicativas, a través de la red, se entienden como tal, pues el terror como método es inoculado en diferentes dimensiones para atentar contra la configuración de la convencionalidad, lo legítimo y lo legal.

La importancia estratégica de la propaganda para los terroristas radica en la exaltación de sus actividades y el mensaje de hacer pública 
su capacidad de destrucción. Esa es la diferencia entre cualquier tipo de delincuencia y el terrorismo contemporáneo: el requerimiento de un hecho comunicativo y la repercusión de sus consecuencias (Veres, 2012). La propaganda terrorista tiene diferentes aristas que concurren en elementos de visualización y promoción del terrorismo como el reclutamiento en aras de atraer adeptos, milicianos, informantes y "afiliados", como si se tratase de un club. En ese sentido, dentro de la misma propaganda los grupos terroristas buscan generar un "sentido de pertenencia" hacia el grupo (como si se tratase de una institución), incitan a sus interlocutores a crear lazos afectivos, de identidad y fidelidad a las causas terroristas. Así mismo, dicha lógica de propaganda tiene su columna vertebral en la radicalización como institución.

Sin embargo, se debe tener en cuenta que la difusión de propaganda no es, per se, una actividad prohibida. Uno de los principios del derecho internacional es la protección del derecho a la libertad de expresión. No obstante, dicho principio tiene ciertos matices cuando aquella expresión y propaganda atenta contra los derechos colectivos, la libertad de otros e incluso contra la seguridad nacional (UNODC, 2013).

\section{Financiación}

Por otra parte, se encuentra el uso de la "financiación" por Internet. En capítulos anteriores se ha hecho alusión a los métodos de captación de recursos como el caso hawala, pero el uso de la financiación por Internet tiene grandes efectos inmediatos que favorecen la causa terrorista.

Según la Oficina de las Naciones Unidas contra la Droga y el Delito (UNODC) los grupos terroristas se valen de Internet y de las operaciones de fácil acceso para captar dinero de cuatro principales maneras (figura 3). 
Figura 3. Tipos de financiación al terrorismo a través del uso de Internet

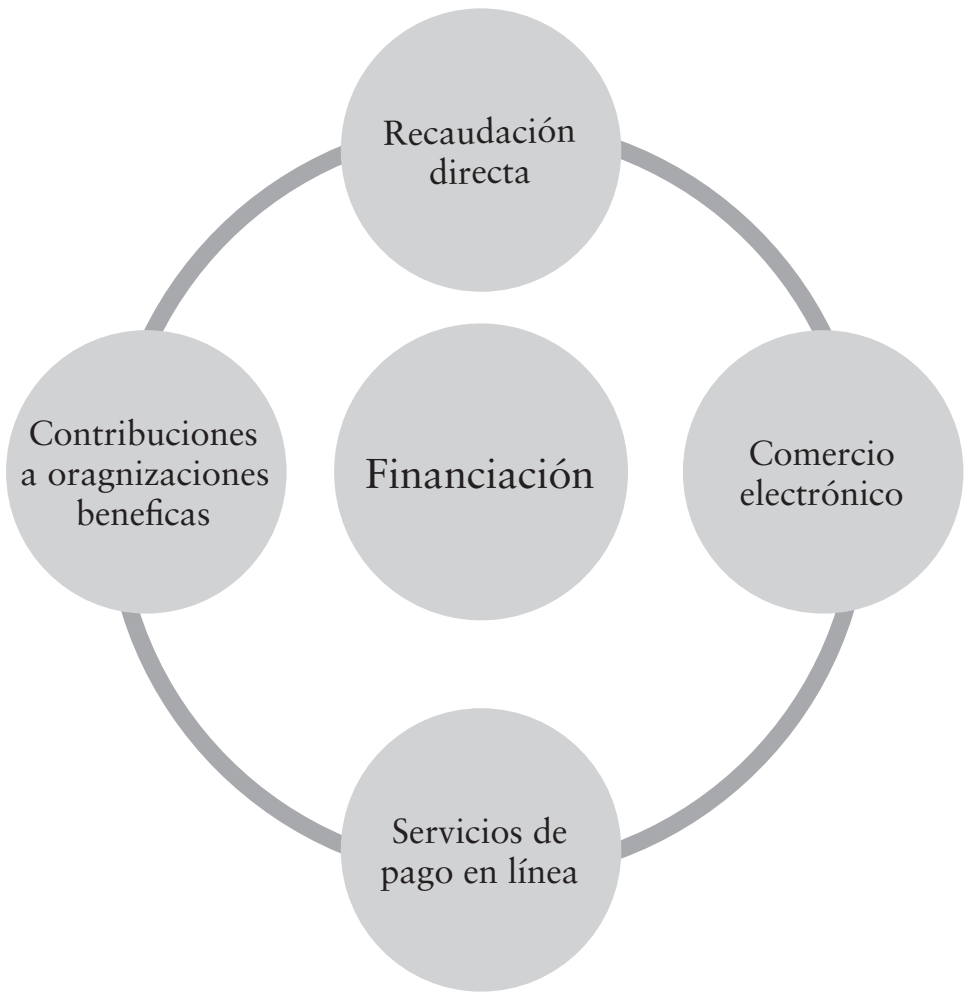

Fuente: edecuado de UNODC, (2013).

La recaudación directa consiste en entablar comunicaciones expresas y puntuales para contribuir a la causa. Luego de haber adquirido potenciales y concretos simpatizantes, el mensaje para donaciones se hace explícito a través de los foros, los chats y los correos electrónicos (UNODC, 2013) de los individuos que se han "institucionalizado". La metodología de la recaudación directa ostenta la posibilidad estratégica respecto a que los servicios de pago en línea pueden ser usados de igual forma por medios oscuros y fraudulentos, como son el robo de la identidad de internautas desprevenidos e incautos, sus tarjetas de crédito y generar hasta fraudes bursátiles (UNODC, 2013); son unos ciber-terroristas que cumplen la función de captar recursos a como dé lugar. "Los delitos contra la propiedad intelectual y el fraude en 
subastas son otros ejemplos al respecto. Un ejemplo del uso de ganancias ilícitas para financiar actos de terrorismo es la causa del Reino Unido contra Younis Tsouli (BBC, 2008)".

El fenómeno de la recaudación directa es un método que articula las otras dimensiones de la financiación del terrorismo, pues la recaudación tiene diferentes caras, entre las que se encuentran el plagio y la donación de adeptos. Así las cosas, otro gran fenómeno que preocupa a las instituciones legales y legítimas, a los operadores de seguridad y justicia es que el terrorismo se vale de supuestas organizaciones benéficas para pasar desapercibido en la captación de dinero y fondos.

El apoyo financiero a organizaciones aparentemente legítimas, tales como las organizaciones benéficas, también puede desviarse hacia fines ilícitos. Se sabe de algunas organizaciones terroristas que han establecido empresas fantasmas, disfrazadas de entidades filantrópicas, para solicitar donaciones en línea. Estas organizaciones pueden afirmar que apoyan causas humanitarias, cuando, en realidad, utilizan las donaciones para financiar actos de terrorismo (BBC, 2008).

A lo largo y ancho del planeta, gracias a la Internet, las comunicaciones y organizaciones fantasmas en pro de las causas terroristas, tienen mayor y mejor dinámica de funcionamiento. El terrorismo es una actividad barata en su conjunto, que no requiere de mayor infraestructura física ni de grandes cantidades de recursos para cometer sus actos; no obstante, los grupos terroristas son los conglomerados criminales de más alto poder adquisitivo. Esto lo logran, entre otras, gracias a las fachadas que elaboran para evitar su detección, y como toda fachada es subterránea, el terrorismo adopta medidas pseudo-institucionales para que ellas funjan como "instituciones".

Lo anterior demuestra una gran sinergia estratégica entre los nodos de la red. El terrorismo comprende un gran cúmulo de opciones para esquivar y pasar inadvertir por las autoridades, precisamente comportándose bajo la figura de "para-institución" con un completo andamiaje financiero que incluso posee propios patrones de cambio, transacciones clandestinas, bancos subterráneos y constantes flujos organizacionales para su configuración terrorista. 
Tabla 5. Algunas organizaciones "benéficas" al servicio del terrorismo

\begin{tabular}{|l|l|}
\hline \multicolumn{1}{|c|}{ Organización } & \multicolumn{1}{c|}{ Breve descripción } \\
\hline $\begin{array}{l}\text { Benevolence } \\
\text { International } \\
\text { Foundation }\end{array}$ & $\begin{array}{l}\text { Organización tipificada como colaboradora y socia } \\
\text { de Al Qaeda. Es sindicada de "participar en la } \\
\text { financiación, planificación, facilitación, preparación o } \\
\text { comisión de actos o actividades por, en conjunto con, } \\
\text { bajo el nombre de, en nombre o en apoyo de ellos", } \\
\text { así como de "suministrar, vender o transferir armas y } \\
\text { pertrechos" o "actos o actividades de apoyo para y } \\
\text { hacia Osama Bin Laden y Al- Qaeda (QE.A.4.01.)". } \\
\text { (Organización de las Naciones Unidas, 2014) }\end{array}$ \\
\hline $\begin{array}{l}\text { Global Relief } \\
\text { Foundation }\end{array}$ & $\begin{array}{l}\text { Ha proporcionado asistencia financiera y recibió } \\
\text { fondos de los individuos asociados con Al-Qaeda. } \\
\text { Mohammed Galeb Kalaje Zouaydi, presunto } \\
\text { financista de los esfuerzos terroristas en todo } \\
\text { el mundo de Al-Qaeda, es un claro ejemplo. } \\
\text { (Organización de las Naciones Unidas, 2014) }\end{array}$ \\
\hline The Holy Land & $\begin{array}{l}\text { Dio dinero a organizaciones de caridad conocidos } \\
\text { como comités zakat que operaban en los territorios } \\
\text { palestinos. Aunque estos no fueron catalogados como } \\
\text { entidades terroristas, el grupo Hamas los controlaba } \\
\text { y el dinero que recogieron benefició la estructura de } \\
\text { and Development } \\
\text { la organización terrorista. Según el Departamento } \\
\text { de Justicia, "HLF ocultó intencionalmente su apoyo } \\
\text { financiero a Hamas tras el disfraz de donaciones de } \\
\text { caridad". (Anti-defamation league, 2004) }\end{array}$ \\
\hline
\end{tabular}

Fuente: adaptado de BBC, (2008).

Frente a las dinámicas estratégicas, Internet se ha convertido en una de las herramientas principales para las causas terroristas. Es la plataforma plausible, barata y eficaz para proyectar muchas de sus nociones de supervivencia como redes terroristas. Para Gabriel Weimann, la dinámica de la virtualidad con el terrorismo tiene una relación especial:

Los terroristas no sólo han demostrado tener mucha habilidad para el marketing en línea, sino también ser expertos en recopilar información de los más de mil millones de sedes que forman la telaraña mundial. Por medio de Internet pueden averiguar los horarios y la localización de objetivos tales como servicios de transporte, centrales nucleares, edificios públicos, aeropuertos y puertos, así como las medidas antiterroristas. Según el secretario de Defensa, 
Donald Rumsfeld, un manual de entrenamiento de Al Qaeda hallado en Afganistán explica a sus lectores que "es posible reunir al menos el ochenta por ciento de toda la información necesaria sobre el enemigo mediante el uso de fuentes públicas y sin recurrir a medios ilegales (Weimann, 2004).

Así las cosas, Internet es una condición de vulnerabilidad y sensibilidad para los entes estatales, los operadores de seguridad y justica, así como para toda la arquitectura convencional, legítima y legal. Internet se ha convertido en un "hoyo negro" donde los flujos de comunicaciones, en muchas ocasiones, se escapan del control de las autoridades; allí, gracias a la dinámica de las libertades de expresión y comunicación, el terrorismo se vale de los principios del derecho internacional para ampararse y aprovechar las fisuras doctrinales, pues invocan principios tales como la no intervención en asuntos internos para evitar persecuciones jurídicas y militares en sus territorios, por parte de fuerzas extranjeras; así mismo, aluden a la libertad de expresión cuando son restringidos sus portales de Internet por tener contenido violento e ilegal, entre otros, para cometer actos atroces.

Internet, más allá de ser una grandiosa herramienta de la globalización para la economía, el mercado y la información, es un reto y desafío de carácter estratégico en la lucha contra el terrorismo.

\section{Adiestramiento a control remoto}

Para que un individuo se convierta en terrorista o haga parte de manera directa o indirecta de alguna organización terrorista, no es necesario un alistamiento complejo y estructural. El adiestramiento terrorista puede ser ejecutado de manera remota. Es decir, para un simpatizante que se encuentre en Estocolmo y que quiera contribuir de distintas maneras a la causa terrorista de las Farc en Colombia, no es imperante saber sobrevivir en la selva, saber disparar un fusil AK-47 o ser experto en explosivos; para adiestrarse no es necesario estar en el centro del centro de las operaciones del grupo, basta con estar en Londres, Bogotá, Madrid, Ámsterdam o París y tener la voluntad de hacerlo. Internet 
facilita la motivación de la voluntad en el adiestramiento, pues a través de la Red es supremamente fácil generar un vínculo a la causa terrorista para el individuo sin necesidad de un desgaste organizacional y movilidad de recursos, basta con una simple pero profunda cautivación.

Frente lo anterior, los grupos terroristas entienden bien la dinámica descrita líneas atrás. Además, dicho fenómeno les facilita incrementar el número de adeptos y el adiestramiento de individuos sin importar que no hablen el mismo idioma, pues el terrorismo se convierte en el idioma universal para ellos.

Varias plataformas en la Red (por ejemplo foros y blogs), que no parecen tener un diseño deslumbrante, son los espacios virtuales donde se instruye acerca de cómo ser un terrorista de una u otra organización. Incluso la puesta en línea de varios videos de distintas organizaciones dando la bienvenida y prometiendo un nuevo enfoque de vida, son los recursos más fáciles y económicos para proyectar un conjunto de parámetros para adiestrar a los futuros colaboradores o miembros del grupo.

En el caso de Al Qaeda, este grupo se ha valido de una revista que ha publicado una versión en inglés para adiestrar y comunicar sus supuestos ideales, se trata de la revista Inspire. La revista cuenta con características que incluyen la metodología sobre "cómo hacer una bomba en la cocina de su mamá" (Foreign Service, 2010). Inspire se configura como una revista de libre circulación, organizada de tal manera que "atrapa" al lector buscando una cautivación temática, filial y estratégica. Su líder máximo es quien escribe la editorial; las páginas siguientes, desarrollan una "para-información" sobre los sucesos mundiales. Inspire intenta contar la versión de los terroristas y satanizar la convencionalidad; sus columnas justifican sus actividades y en la parte final, como si se tratase de un recetario de cocina, están los pasos para hacer bombas y armas caseras ${ }^{23}$.

Como el caso de Inspire hay cientos de portales y plataformas para adiestrar a futuros terroristas. Basta con citar otro ejemplo: el portal de Anncol, un espacio exclusivo para potenciar, comunicar y masificar de

23 La revista Inspire está disponible on-line y es un instrumento que permite al internauta tener acceso y así poder adiestrarse como un potencial terrorista. 
manera rápida y precisa — con jerga entendible — las dinámicas y causas de las Farc en Colombia. Anncol tiene su dominio web (registrado en Europa), lo cual corrobora la idea de que el terrorismo se ha valido de Internet para viralizar sus acciones. Basta con tener acceso a la Red para recibir o encontrar información sobre cómo convertirse en terrorista.

\section{Planificación}

Los portales de Internet se han convertido en vitrinas para la idea, planificación y ejecución de los actos de terrorismo. La planificación, a la luz de las autoridades y operadores de seguridad, no es tan clandestina como pareciera. Evidentemente el terrorismo es más efectivo mientras más miedo y terror se genere, en virtud del un anuncio previo de un ataque. Esto lo entienden los grupos terroristas, incluso saben bien anunciar los actos con sus respectivas restricciones. Los grupos terroristas, en muchas ocasiones, planean sus atentados y los dejan positivizados en sus portales de Internet, sin mencionar quién, cómo o cuándo sucederán; sólo les basta publicar que detonarán una bomba o algo parecido con lo cual el simple hecho de poner en alerta máxima a las autoridades, los operadores y a la población civil es justo para sembrar pánico colectivo y terror.

No obstante, así como hay partes públicas sobre la planificación de sus actos, también existen comunicaciones secretas entre los principales nodos de las organizaciones. La planificación está ideada y estructurada desde los nodos internos, es más, la puesta en público de la planificación responde a una planificación del hecho, es decir, la publicación de los planes ha sido consensuada entre los miembros del grupo. La planificación está directamente relacionada con todos los arquetipos de interacción interna en el grupo. Así, por ejemplo, aunque parezca sencillo poner un artefacto explosivo en un objetivo clave, detrás de la postura de dicho objeto hay todo un teatro de programación, en el cual la participación de los principales nodos de la red es fundamental. No hay que olvidar que el terrorismo busca el impacto sobre el imaginario colectivo, lo cual significa que el impacto de terror esperado 
Figura 4. Proceso de publicación de los planes

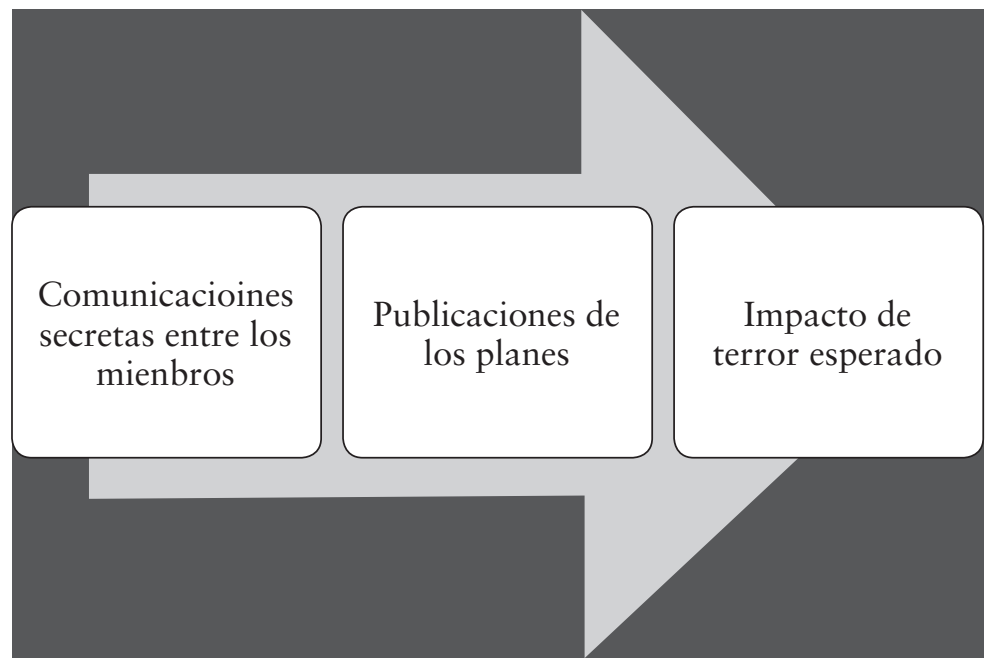

Fuente: elaboración propia

debe ser proporcional al diseño del ataque para que satisfaga las intenciones del grupo terrorista en cuestión.

\section{Ejecución}

Cuando se abordan los temas sobre la ejecución de planes y proyectos terroristas, hay bastante documentación de análisis en inteligencia y contrainteligencia, en materia contraterrorista, para entender su procedimiento interno; no obstante, es relevante aclarar que uno de los principales errores de los operadores de seguridad y de las agencia de inteligencia es que han intentado unificar los criterios de acción de los grupos de manera universal, cayendo en la trampa dinámica que cada grupo tiene una manera distinta de operar, empero comparten algunos elementos básicos para llevar a cabo la ejecución de los planes.

El desarrollo de los planes se entiende como la ejecución de los mismos. En ese orden de ideas, el terrorismo se vale de procedimientos internos que responden a una serie de códigos y normas para llevar a cabo los actos. La ejecución se implementa teniendo en cuenta 
que los actores dentro de la organización son racionales y actúan de una manera no convencional frente a la dinámica de costo-beneficio.

Como todo proceso organizacional, la ejecución responde a una lógica funcionalista, en la cual cada individuo, cada actor y cada interconexión trabaja de manera concatenada en la puesta en escena del planeamiento. El terrorismo se vale de dinámicas estratégicas para activar los proyectos en los que no se necesita mayor costo de transacción para hacerlo. Debido a su naturaleza subterránea, su configuración en red y trabajo por células o facciones que responden a un comando central y estratégico o en su defecto a su propia naturaleza de organización, que en ocasiones resulta bastante sencilla; la ejecución de los planes, aunque parezca ilógico en muchos momentos, no tienen que ser consultadas de manera previa con los actores estratégicos, pues sería un riesgo que en el flujo en doble vía de la información, las órdenes y la consulta fueran interceptados por las autoridades legítimas y convencionales.

Metodologías y estructuras internas en las organizaciones terroristas hay varias, es decir, el sistema de procedimiento dentro de Al Qaeda, las Farc, Boko Haram, el Estado Islámico, entre otros, no es el mismo aunque tienen similitudes. La ejecución de los planes para llevar a cabo los ataques terroristas dentro de cada grupo responde a códigos internos propios, pero comparten en términos generales la configuración de nodos, funciones, responsabilidades, códigos, normas y parámetros para ejecutar.

\section{Ciber-ataques}

El terrorismo comprende bien que el uso de las tecnologías es una herramienta plausible para la puesta en escena de sus planes. Saben bien que se corren menos riesgos si se sistematiza, desde ordenadores y circuitos virtuales, la información, como también que son menos vulnerables (a pesar de las estrategias contraterroristas en la red) ${ }^{24}$ porque

24 Por ejemplo la creación de ciber-comandos son algunos de los casos concretos que desde la legalidad y convencionalidad se hacen para contrarrestar y anticipar movimientos terroristas por el ciberespacio. 
ponen menos capital humano y físico en riesgo, al tiempo que potencian la capacidad de destrucción con simples comandos remotos. "Un ciberataque generalmente se refiere a la explotación deliberada de redes informáticas como medio de lanzar un ataque. Estos ataques suelen estar destinados a perturbar el funcionamiento normal de los blancos elegidos, como los sistemas de computadoras, servidores o la infraestructura subyacente" (UNODC, 2013).

Esta nueva dimensión del terrorismo es supremamente útil y eficaz. Con unos cuantos comandos se puede afectar la vulnerabilidad de varios blancos y objetivos, entre ellos gobiernos, bancos, sedes de campañas políticas, oficinas gubernamentales, centrales energéticas, acueductos y hasta el sistema financiero en general. Cabe resaltar que los ciber-ataques no son una herramienta exclusiva de los grupos terroristas, pues algunos Estados se han valido de dicho instrumento como sistema de defensa y ataque contra otros Estados.

La puesta en marcha de los planes y ejecuciones terroristas viajan por el ciberespacio con una doble intención. La primera de ellas, aunque parezca poco lógico, es ser "detectados" por los ciber-comandos de los operadores de seguridad de los Estados para generar terror y poner en alerta máxima a las autoridades y sembrar pánico colectivo. La segunda es eliminar cualquier rastro físico y pasar inadvertidos.

Con esa intención el rango de impacto es mucho mayor que la simple postura de un carro bomba en alguna estación de metro, pues la exposición a la captura es mucho menor y pueden poner la impronta o sello "institucional" del grupo vía internet como mensaje final del atentado. El terrorista hace clic y puede atacar varios blancos, cerrar su computador portátil y huir a otro espacio geográfico, o simplemente deshacerse del aparato y poner fin a la cadena que en algún momento pudiera involucrarlo en el siniestro.

\section{Las “doctrinas” del terrorismo: instituciones naturales}

La concepción de doctrina tiene varias dimensiones, dependiendo del enfoque epistemológico que se le desee otorgar. Al referirse a doctrinas, 
se abre un abanico con distintas posibilidades semánticas, disciplinares y de construcción de conocimiento. La doctrina es una palabra que ha estado inmersa en distintas formas en la sociedad: la formación del Estado-nación, la explicación jurídica de algún tema del derecho, los modos de procedimiento estratégico en la dimensión militar hacia la seguridad nacional, los parámetros educacionales de los diferentes sistemas de los países, las concepciones teológicas e interpretaciones de las escrituras en las distintas religiones, etc. En ese orden de ideas, es fundamental que conciba la doctrina, en materia de terrorismo, como ese cúmulo de patrones procedimentales de sus propias organizaciones como una nueva dimensión del término.

La doctrina es entendida, en términos jurídicos, como las opiniones expertas de juristas referente a los temas del derecho; la doctrina puede ser interpretada también como una fuente aclaratoria y de consulta donde confluyen los pensamientos y creencias a través de la enseñanza de la disciplina, es la extensión de las interpretaciones (Cámara, 2006). La doctrina es, sin duda, una institución dentro del derecho con menor rango y grado que la Ley en sentido amplio, la costumbre y los principios rectores y generales del derecho, pero es un factor fundamental en las interpretaciones jurídicas (Cienfuegos \& López, 2005). Por otro lado, cuando se refiere a cuestiones estatales, en términos de política del Estado, es concebida como el asunto que entiende el Estado por determinado fenómeno ${ }^{25}$. En ese orden de ideas, el terrorismo logra fungir las dos dimensiones frente a la lógica doctrinal, por un lado la condición de sumatoria de creencias y procedimientos de acción y por otro lo que el mismo terrorismo considera y entiende por algún fenómeno en particular.

En primer lugar, la configuración del terrorismo como un régimen internacional subterráneo identifica patrones en sus actividades como organización y como sistema de amenaza al sistema internacional. De esa manera es relevante mencionar que el terrorismo tiene doctrinas y

25 Por ejemplo cuando se analizan las doctrinas de seguridad o de política exterior de los Estados, se debe observar el fenómeno respecto a lo que el Estado considera y entiende por seguridad y por interés nacional frente a la política exterior. 
es por esa razón que como organizaciones responden a lógicas estructurales en sus más profundas dimensiones.

El terrorismo, como fuente de su configuración y existencia (doctrina), considera que con sus actividades se puede cambiar un orden ya establecido. Por esa razón, las doctrinas de los terroristas conciben las diferentes metodologías para alcanzar sus objetivos estratégicos por vías subterráneas como los atentados suicidas, las inmolaciones, los carros bomba, collares explosivos, el ciber-terrorismo, entre otras.

Claramente la concepción cosmogónica del terrorismo varía tectónicamente, dependiendo de su naturaleza gestacional. De ese modo, hay que tener en cuenta las reglas y parámetros de los distintos grupos alrededor del mundo que convergen en una metodología común que es el terrorismo, pero se distancian en el "cómo" de sus actividades. Así, por ejemplo, la doctrina de Al Qaeda no es la misma de las Farc ni la de Boko Haram.

En ese sentido, es importante analizar las condiciones doctrinales que el terrorismo en general puede tener como fuente institucional de sus actividades. También es válido mencionar que el terrorismo tiene doctrina.

\section{Teo-terrorismo: doctrina fundamentalista}

El componente teológico tiene un importante cimiento dentro de las estructuras terroristas en Medio Oriente. Es una piedra angular en la interpretación de los textos sagrados sobre la rendición, reivindicación y salvación. Así las cosas, los principios teológicos consagrados en las escrituras fungen como directrices rectoras y como doctrinas de la razón de ser de algunas de las agrupaciones terroristas.

En efecto, en agosto de 1996 Osama bin Laden publica un mensaje en $\mathrm{Al} Q u$ us $\mathrm{Al} \mathrm{Arabi}{ }^{26}$ rotulando sus declaraciones y haciendo mención a "la declaración de guerra contra los americanos que ocupan los territorios sagrados" (Gracía, 2008, p. 23). Es la materialización concreta de

26 Periódico independiente de cuestiones árabes en Londres 
una doctrina de empleo del terror contra un enemigo creado desde la concepción religiosa pasando por la política, estratégica y hasta militar.

El prisma teológico es una primera especie de doctrina interna del terrorismo, a saber, el teo-terrorismo ${ }^{27}$, manifestado en una dimensión del Islam como la yihad, es la fuente principal del deber ser del practicante y miembro activo del grupo. Así las cosas, "la yihad es el esfuerzo que todo musulmán debe realizar para que la ley divina reine en la Tierra" (Diccionario Manual de la Lengua Española, 2015), es la doctrina que emana un decreto religioso para extender la ley y la voluntad de Dios (Martínez, 2009). No obstante, la doctrina y ley teo-terrorista responden a un extremismo y radicalismo de una interpretación de la fuente procedimental de los códigos religiosos para la violencia extrema.

El terrorismo islamista no es la consecuencia inevitable de la doctrina islámica, sino el producto de una determinada lectura del Islam y de una peculiar interpretación del discurso islámico de legitimación de la violencia. En este, como en otros aspectos, la doctrina musulmana no es unívoca, ni tampoco las reacciones que el discurso islamista suscita en el seno de las propias sociedades musulmanas (Gracía, 2008, p. 23).

Las doctrinas terroristas pueden ser elaboradas bajo la concepción legítima de lo mencionado anteriormente como el terrorismo positivo, una configuración de lo que los terroristas entienden por el orden de las cosas, las causas y el poder de legitimidad que dan las instrucciones doctrinales para encausar las acciones por la satisfacción y cumplimiento de las leyes religiosas. El teo-terrorismo es la manifestación del fuero y amparo de la interpretación de las escrituras adicionando elementos condicionantes como el de amigo-enemigo.

La noción del enemigo es otra fundamentación de la manifestación doctrinal del terrorismo. Identificar un enemigo es clave para que el grupo tenga legitimidad de acción. Con dicha legitimidad se configura una doctrina discursiva de construcción política sobre las dimensiones

27 Término acuñado por el autor 
del mensaje radical para combatir al configurado enemigo. Los manuales de procedimiento, más allá de las leyes religiosas y los regímenes teológicos, tienen mayor cabida en la condición acomodada a la estratégica de lucha y terror.

\section{Doctrina intelectual del terrorismo: caso Farc y su derecho constitucional subterráneo}

Gran parte de los grupos terroristas invocan cuestiones teológicas y filosóficas para legitimar parte de sus acciones y justificar su existencia. Desde la citación e invocación de manuscritos de profetas, hasta la de autores clásicos y contemporáneos como fuente de inspiración doctrinal, son el centro de gravedad de la causa terrorista. La interpretación de dichos autores y sus conceptos son las columnas vertebrales para la configuración de los grupos.

No obstante, varios de los grupos, al interiorizar los preceptos y marcos teóricos para generar sus doctrinas filosóficas, caen en contradicciones sustanciales con sus apuestas teóricas. En el caso de las Farc en Colombia, que desde su momento fundacional se denominaron marxistas, entran en una profunda contravía con el Manifiesto del Partido Comunista (1848) de Marx y Engels que pretendía una revolución social a través del proletariado, mientras que el grupo se conformó en algún momento como una organización "campesina” que esperaba que el proletariado se sumara a su lucha (Fort, 2013).

Otra contradicción profunda de las Farc es que en sus declaraciones primarias e incluso contemporáneas, aluden a que buscan cambiar el sistema capitalista reinante en el sistema colombiano, pero los hechos demuestran que el grupo no busca el cambio del sistema capitalista, pues son el tercer grupo terrorista que más dinero tiene en el mundo después del Estado Islámico y Hamas, respectivamente. Una contradicción de doctrina incluso económica que se suma a las demás.

En cuanto a las directrices estratégicas sobre cómo es el procedimiento para la toma del poder en Colombia, las Farc han tenido varias 
modificaciones doctrinales desde sus inicios. Desde que se consolidaron como un movimiento guerrillero, en los años sesenta, han pasado por mutaciones de carácter misional importantes, incluso hasta los rótulos de "conferencias" que son los eventos y reuniones de élite dentro de la organización que sacan documentos con las conclusiones y pasos estratégicos a tener en cuenta para potenciar sus actividades, golpear al Estado y tomarse el poder.

Uno de los hitos fundacionales de la doctrina de las Farc es la "Lucha Revolucionaria del Programa Agrario". En palabras de Astrid Vargas, haciendo referencia a la Séptima Conferencia de las Farc de 1982 y al Programa Agrario:

Dicho aspecto da inicio y define la orientación, donde la causa ya no era la autodefensa sino la lucha por los cambios y el poder político, se convierte en una guerrilla móvil revolucionaria. Este hecho, que ha sido el más significativo para el grupo armado ilegal, da origen al movimiento que durante la Segunda Conferencia Nacional en mayo de 1966, en Casa Verde, recibió el nombre de Fuerzas Armadas Revolucionarias de Colombia (Farc).

Desde el enfoque histórico, para algunos comandantes guerrilleros el principio fundacional significa "estar siempre al lado del pueblo, lo cual representa resistir, que simboliza todo, porque es a nivel armado, político e ideológico" (Arenas, 1982). Dentro de la organización subversiva, este llamado "mito fundacional" sirve como elemento cohesionador y de impulso moral en momentos críticos (Vargas, 2014).

La dinámica de las doctrinas intelectuales del terrorismo es la base estructural de la metodología de acción de los grupos. Por ejemplo, otro aspecto relevante frente a las Farc es la construcción de un "estatutos", en forma de un documento, que recoge todos los insumos intelectuales, filosóficos, pragmáticos y estratégicos; de hecho es la hoja de ruta, en materia doctrinal, sobre las aspiraciones y evoluciones de sus causas. En otras palabras, los “estatutos” cumplen el mismo papel de una Constitución subterránea. 
Así las cosas, el terrorismo de las Farc responde a la doctrina implementada y "positivizada" en una serie de documentos rectores que motivan la funcionalidad de la organización. Dentro de los "estatutos” están consagrados los códigos de procedimiento, la rendición de cuentas para los integrantes del grupo, las responsabilidades de las unidades y células, los deberes y derechos de los miembros de las Farc, su simbología (el himno, la bandera y el emblema), el reglamento de procedimiento disciplinario y en él lo que se considera como irrespeto, crímenes y faltas de los individuos del grupo para la organización y su deber ser, así como las normas internas de su comando.

En las normas está estipulada la metodología organizacional, la construcción de sus bases militares y la conformación de su estructura. Su configuración como grupo terrorista está enmarcada en los siguientes niveles estratégicos, tácticos y operacionales:

Tabla 6. Estructura militar de las Farc

\begin{tabular}{|l|l|}
\hline \multicolumn{1}{|c|}{ Nivel } & \multicolumn{1}{c|}{ Descripción } \\
\hline Estado Mayor Central & $\begin{array}{l}\text { Órgano superior de dirección mando y control de } \\
\text { las Farc. Sus instrucciones y órdenes son obligantes a } \\
\text { todos los niveles e integrantes }\end{array}$ \\
\hline Comando General & Son quienes dirigen la ofensiva \\
\hline Comando Conjunto & $\begin{array}{l}\text { Dependen del Estado Mayor Central y son quienes } \\
\text { unifican y coordinan las acciones de los frentes en } \\
\text { áreas determinadas }\end{array}$ \\
\hline $\begin{array}{l}\text { Estados Mayores de } \\
\text { Bloques }\end{array}$ & $\begin{array}{l}\text { Coordinan, en las áreas de los bloques, las campañas } \\
\text { militares y los planes de las Conferencias. Centralizan } \\
\text { las relaciones políticas en los bloques y ejecutan el } \\
\text { desarrollo de los planes particulares de los frentes }\end{array}$ \\
\hline Bloques de Frentes & $\begin{array}{l}\text { Consta de } 5 \text { o más frentes. Coordina y unifica } \\
\text { las actividades de los frentes de acuerdo al "Plan } \\
\text { Estratégico de las Farc" }\end{array}$ \\
\hline Frente & Consta de más de una columna \\
\hline Columna & $\begin{array}{l}\text { Consta de } 2 \text { compañías o más con sus mandos. } \\
\text { Alrededor de } 110 \text { hombres }\end{array}$ \\
\hline Compañía & $\begin{array}{l}\text { Consta de } 2 \text { guerrillas más sus mandos, que son } \\
\text { alrededor de } 54 \text { hombres }\end{array}$ \\
\hline Guerrilla & $\begin{array}{l}\text { Consta de } 2 \text { escuadras más sus mandos, que son } \\
\text { alrededor de } 26 \text { hombres }\end{array}$ \\
\hline
\end{tabular}




\begin{tabular}{|l|l|}
\hline \multicolumn{1}{|c|}{ Nivel } & \multicolumn{1}{c|}{ Descripción } \\
\hline Escuadra & $\begin{array}{l}\text { Unidad básica de la estructura guerrillera. Consta de } \\
12 \text { hombres junto con sus mandos }\end{array}$ \\
\hline
\end{tabular}

Fuente: Farc-Ep, (2014).

La anterior estructura es la muestra concreta de la doctrina procedimental para las Farc (Torrijos, 2012). Esto significa que el grupo terrorista tiene unos parámetros establecidos para actuar y una serie de instrumentos adoptados dentro de su organización para planear, ejecutar y actuar. De esa manera, es evidente que la Constitución subterránea de las Farc responde a una lógica de orden determinado al estilo de un "derecho constitucional subterráneo".

Su doctrina intelectual ha sido, de alguna manera, el centro de gravedad en la configuración del grupo y sus actividades. Las Farc, al igual que los demás grupos terroristas alrededor del mundo, funcionan estructuralmente bajo doctrinas.

\section{Concatenación de doctrinas: complejos complementos}

La metodología del combate, economía subterránea, guerra de movimientos, guerra de guerrillas, uso de explosivos, materiales y armas no convencionales, secuestros, ejecuciones extrajudiciales y demás; son parte del conjunto de las dinámicas internas de las acciones de los diferentes grupos terroristas.

El terrorismo funciona, entre otras, gracias a las asociaciones estratégicas entre los mismos grupos. Es una gran empresa que, fuera de las dinámicas ideológicas, tiene grandes nexos doctrinales sobre su financiación, proyección y metodologías en la siembra del terror. Los diferentes grupos - independientemente de su mito fundacional, toma de decisiones interna, doctrina natural, inspiración filosófica o intelectual- se concatenan en tres puntos doctrinarios específicos: el tráfico ilícito (drogas y armas), la incorporación de miembros combatientes no convencionales y la mujer como campo de batalla. 
Sin importar a qué grupo se esté haciendo referencia, las doctrinas frente al tráfico ilícito, la incorporación de miembros combatientes no convencionales y la mujer como campo de batalla parecen haber sido un copy paste de los diferentes grupos terroristas. La concatenación de sus metodologías en dichas dimensiones es tan semejante que entre ellos se han vuelto socios estratégicos en las dinámicas de sembrar terror.

En ese orden de ideas, para citar tan solo un ejemplo, en el año 2013 se publicó un informe de la Agencia Antidroga de Estados Unidos - DEA, respecto a la concatenación de operaciones de narcotráfico entre las Farc y Al Qaeda. En él se denunciaba una asociación subterránea en la cual ambas organizaciones terroristas tenían un centro de operaciones compartido en el Magreb Islámico para introducir la droga desde Turquía a toda Europa (El País, 2014).

Esta ha sido la primera ocasión en que se halla constancia policial de una red de colaboración entre grupos de Al Qaeda en el Magreb y la guerrilla colombiana. Según fuentes de la agencia antidroga de EE UU, los contactos fueron establecidos meses antes del intercambio por colaboradores de las FARC que viajaron a Argelia para contactar y establecer el acuerdo. El contacto se hizo a través de miembros de Al Qaeda en el Magreb Islámico y el intercambio a través de salafistas que controlan esa zona y que se mueven bajo las directrices de los integristas islámicos. Según la investigación, los colombianos también recibieron una importante cantidad de dinero por parte de los salafistas integristas (El País, 2014).

Por otro lado, la dimensión de la incorporación de miembros combatientes no convencionales es una constante en los grupos terroristas en general. Las Farc, Al Qaeda, el Estado Islámico, Hezbollah, entre muchos otros, han configurado metodologías similares para adoctrinar niños y menores en sus filas terroristas. Eso con el objetivo estratégico de ser más letales y prolongar un legado estructural con miras a proyectar una para-sociedad o sociedad subterránea. Dichos niños y menores crecen con la convicción doctrinal que la única, viable y legítima forma de vida es el terrorismo sin saber que son terroristas. 
Los registros de las Fuerzas de Defensa de Israel, así como otros entes operadores de seguridad, para poner un ejemplo concreto, han documentado que:

El movimiento juvenil Imam al-Mahdi, como ejemplo de un movimiento afiliado a Hezbollah, enseña la doctrina de la "resistencia", las tácticas militares y educa sobre el Islam radical iraní. En una de las últimas ediciones de la revista, diseñada para niños de 4 a 7 años de edad, se enseña sobre los méritos del "martirio" (Israel Defense Forces, 2014).

Otro gran ejemplo es que el Estado Islámico se ha valido de diferentes estrategias "pedagógicas" para enseñar a los niños a decapitar. Por Internet circulan videos en los cuales se usan muñecos para que los menores practiquen en campos de entrenamiento ubicados en Raqqa Siria (El Comercio, 2014). En efecto, el adoctrinamiento de menores es un insumo crucial, estratégico y del más alto valor constitutivo para los grupos terroristas.

Hay un serio marco de adoctrinamiento terrorista para los niños y menores. Desde "bautizarlos" en un régimen terrorista para la lucha de determinada causa con raíces religiosas o políticas, hasta el alistamiento en el uso de las armas como niños soldados. Esta es sin duda una flagrante violación a los Derechos Humanos, que además va en contravía de los principios del Derecho Internacional Público.

De ese modo, sin importan la naturaleza y procedencia de los diferentes grupos, todos ellos comparten la visión estratégica en el uso de niños y menores como puntas de lanza en sus actividades terroristas. Son unos insumos que representan una ventaja frente al enemigo ya que, por principios convencionales de la guerra, los Estados y sus operadores de seguridad convencionales tienen protocolos muy bien definidos que hacen parte de los lineamientos del Derecho Internacional Humanitario y los Derechos Humanos para no atacar zonas específicas en las que haya población vulnerable, en este caso los niños. Así las cosas, los diferentes grupos utilizan a los menores como escudos humanos y como agentes obstaculizadores. El uso de niños soldados, es un punto en el que convergen las doctrinas de los diferentes grupos terroristas. 
La última dimensión tiene que ver con la concatenación de doctrinas en el uso de la mujer como campo de batalla. Esta es una metodología de guerra que se usa e implementa para ciertos objetivos de carácter estratégico, político y social. El uso de la mujer como campo de batalla tiene que ver con las violaciones y el abuso sexual de mujeres y niñas; dichos actos repercuten en la destrucción del tejido social del enemigo e incluso para inocular las cepas de violencia y engendrar niños producto de una violencia sistemática.

Los grupos terroristas se han valido de esta doctrina como si se tratase de una cruzada social, se valen del cuerpo de la mujer para violentarla sexualmente en aras de consolidar su estrategia de guerra y generar terror por otros medios (Mesa de trabajo. Mujer y Conflicto, 2008). Para precisar las condiciones metodológicas, el Estado Islámico cuenta con un manual de procedimiento en el cual se encuentra positivizado una serie de preguntas y respuestas sobre cómo y bajo qué circunstancias está permitido violar a las mujeres y niñas secuestradas ${ }^{28}$ (que ellos llaman esclavas). Es una clara muestra sobre la doctrina del terrorismo sexual que ostentan diferentes grupos. El documento publicado por el grupo tiene 27 interrogantes, a manera de "preguntas frecuentes” bajo la Ley Islámica; allí queda plasmado que es lícito el tráfico, violación, comercialización y explotación de sus esclavas sexuales.

Dicho texto es el código de procedimiento para el uso de la violencia contra los esclavos, una doctrina asimilada por los integrantes que se debe cumplir en todos los niveles de la estructura. Evidentemente la metodología de la mujer como campo de batalla responde a una doctrina que han implementado los grupos terroristas para proyectar por otro medio el terror y generar una prospectiva de largo plazo en la ruptura de los tejidos sociales de los pueblos.

Es importante resaltar que, aunque al referirse en sentido estricto de estrategias o adoctrinamiento de menores y del uso de las mujeres

28 El informe fue publicado el 4 de diciembre de 2014 por el Instituto de Investigación Mediática de Oriente Medio y se titula Estado Islámico (ISIS) Libera folleto sobre esclavas. En él se recogen las condiciones y reglas para poder violentar a las mujeres. (Ver: The Middle East Media Research Institute, 2014). 
como campo de batalla, esta no es necesariamente una condición concreta de doctrina en términos jurídicos; sí lo es cuando se enfatiza en que dichas acciones son compartidas por los diferentes grupos y gozan de cierta aceptación en el uso, en la creencia, en las ideas para sustentar una metodología válida de lucha en la siembra del terror.

\section{Conclusiones}

Las instituciones del terrorismo son las piedras angulares y estructurales que hacen del fenómeno un actor de alto impacto. Sus normas, códigos, doctrinas y constituciones subterráneas —entendidas como las cartas y hojas de ruta fundacionales y misionales del grupo-fungen un papel primordial en la elaboración de procedimientos que ponen en riesgo y amenazan la seguridad internacional. Las instituciones subterráneas del terrorismo configuran de manera compleja un régimen internacional subterráneo, el cual —desde paradigmas filosóficos, religiosos y políticos-impulsa estratégicamente los métodos de proyección de su actividad.

La intencionalidad de buscar las asociaciones oscuras radica en la salvaguarda de sus propios intereses y, en ese sentido, formar un complejo militar industrial, económico y social subterráneo, en el cual la arquitectura de sus doctrinas se complementa una a otra, y cada grupo se convierte en "especialista" en determinado insumo o servicio. Unos son expertos en el tráfico de drogas, otros en la adquisición y venta de armas, otros en tráfico de personas, ciber-ataques, captación de dinero por parte de organizaciones (supuestamente benéficas), piratería, entre otras. La arquitectura terrorista tiene instituciones altamente aceptadas y legítimas dentro de sus estructuras para mantenerse con vida.

Desde Internet como rampa y sus diferentes componentes que hacen de él un insumo de gran importancia y valor en la masificación de sus acciones, pasando por las doctrinas de los diferentes grupos, hasta la concatenación de las mismas, es que se puede afirmar que el terrorismo - sin importar su lógica gestacional o naturaleza- responde a una constante doctrinal en tres elementos fundamentales: tráfico 
ilícito, reclutamiento de menores para el combate y el uso del cuerpo de la mujer como campo de batalla.

Son las instituciones las que hacen de un actor el cuerpo natural y la configuración del mismo, en ese orden de ideas, la institucionalidad del terrorismo está debidamente diseñada con lógicas subterráneas que, en principio, son paralelas a las convencionales legales y legítimas. Con ellas, la estructuración de las doctrinas dentro de la fenomenología del terrorismo tiene que ver con los patrones de comportamiento, diseño jerárquico, normas de procedimiento, códigos de comunicación, rangos y poder.

El terrorismo ostenta doctrinas que, al concatenarse, hacen del terrorismo un fenómeno que avanza mucho más rápido que las estrategias y doctrinas de los Estados, operadores de seguridad convencional y en sí de todo el sistema jurídico nacional e internacional. Las doctrinas del terrorismo, al ser los puntos neurálgicos de sus actividades, al mismo tiempo representan una vulnerabilidad a su sistema. La cuestión es que los operadores de seguridad y justicia convencionales deben anticiparse a los pasos doctrinales para salirle al paso a las condiciones estratégicas. 
